\title{
Research of the Typical Supply Chain Management Models of the Garment Industry in China
}

\author{
Hao Song \\ Business School, University of Shanghai for Science and Technology, Shanghai 200093, China \\ E-mail: songh@k-boxing.com \\ Chongjun Fan (Corresponding author) \\ Business School, University of Shanghai for Science and Technology, Shanghai 200093, China \\ E-mail: cjfan@sh163.net
}

Received: June 25, 2012

Accepted: July 9, 2012

Online Published: September 12, 2012

doi:10.5430/ijba.v3n5p78

URL: http://dx.doi.org/10.5430/ijba.v3n5p78

\begin{abstract}
Due to the shortage of capabilities in research and development of new products, long designing circle and other factors, China's garment industry has still been accompanied with a traditional supply chain, which is slow in response speed, lagging in logistics and deficient in innovative abilities. This paper firstly made a brief analysis of the current conditions of the traditional garment industry, then described supply chain model of four well-known garment enterprises, including classical Sell-one-Replenish-one model, SEMIR Production-Distribution collaboration model, JOEONE Production-Distribution collaboration model and YOUNGOR "Wine cup" model, and finally summarized some experience, expected to be a reference for China's garment industry to improve their supply chain in future.
\end{abstract}

Keywords: Garment industry, Supply chain, Supply chain management

\section{Three Forms of Competition in China's Garment Industry}

The garment industry in China is still a labor-intensive industry, with remarkably uneven in overall development. Geographically, the garment industry is primarily centered in Guangdong, Jiangsu, Zhejiang, Fujian, Shandong, Shanghai and other south-east coastal provinces. Products from the abovementioned provinces account for more than $80 \%$ of China's market share. Some garment groups in these areas are featured with enormous scale and global business, their annual turnover can reach a few billion yuan or even a few tens of billion yuan. However, the garment industry in the mid and west China is very underdeveloped, where the competition between garment enterprises stays at a lower level and most garment enterprises sell their products primarily through wholesale markets.

With intensifying domestic and foreign competition, three forms of competition have developed in China's garment industry. The first form is purely contract processing enterprises which aim at "delivering products with the right quality, at the right time and at the right place". The main operation of such enterprises is to accept and finish the orders for processing with supply material from domestic and foreign clients. Although the profit margin is low, the enterprises are able to grow steadily as they only face low level of competition and employ simple management techniques.

The second form is "virtual enterprises" which objective is to establish and improve their own brands. Such enterprises focus on investigation of end customer behavior, product development based on research results and, meanwhile improve their own distribution and sales network. A typical example is "Meters/Bonwe" from Wenzhou.

The third form is those enterprises which integrate supply, production and distribution for themselves. Such enterprises not only need to establish strategic and cooperative relationship with upstream suppliers and downstream distributors, but also have to possess strong capabilities of R\&D, manufacturing, and brand management. Hence, the major challenge facing such enterprises is how to establish the core competences. Typical examples are "FIRS" and "YOUNGOR".

Enterprises in various competition forms are active to different extent in various sections of supply chain. However 
many garment enterprises of China still stay in the first form of competition, deficient in the abilities of marketing, designing and R\&D.

Furthermore, China's garment market is seen severely homogenized while customers' demands are becoming increasingly exacting - the market need more and more fashionable and featured brands to satisfy their demand. Thus major garment manufacturers and distributors have started competition over channels and supply chain management. If a competitive man's garment brand want to excel out of the fierce market, the supply chain management is particularly important. Only with solid supply chain as the guarantee, a company can design, manufacture and sell products catering to the consumers at the first time.

Under such circumstance, China's major garment brands have started carrying out various supply chain optimization projects. They attempt to improve their supply chain management level through structural optimization, method improvement and efficiency improvement for all stages of supply chain.

\section{Classical Sell-one-Replenish-one Model}

Sell-one-Replenish-one is the short name for a classical demand-pulled sales model. It advocates centralized management of products and quick replenishment based on a store's sales; this model can effectively solve inventory problems for an enterprise.

The headquarters (HQ) is exclusively responsible for inventory and production; store managers are only in charge of sales and regularly report sales performance to the HQ. The HQ replenishes goods according to the sales performance and may also make a plan for stores' promotion based on sales progress. Employing this model can help a company reduce its inventory-to-sales ratio, boost store efficiency, clear up product management procedures and therefore improve replenishing efficiency.

When adopting this model, 5 key strategies are worth noting:

(1). Ordering based on store.

(2). Stores keep the minimum inventory and the HQ quickly responds and replenishes one after one sold.

(3). Product managers focus on the production and store managers concentrate on sales.

(4). On basis of each style, respond to market at the same logistics response frequency.

(5). Improve the capabilities of product managers.

Meanwhile, the enterprise must be clear about the operational objectives of such model: unimpeded allocation of goods, rapid sales of best-selling products, and prompt promotion with minimum discounts. Achieving these objectives can help the enterprise improve the retail performance.

This model is actually represented by a set of product management rules directing the product flow. Firstly, it requires store-based ordering and distributes goods based on the principle of one piece per size for each style. Then, it sets priority for each store and products from inventory will be replenished to stores according to the priority of each store. Next, the HQ carry out Sell-one-Replenish-one according to sales. Meanwhile, the HQ can trace the sales speed of each style and turnover time of remaining inventory and formulate solutions for dull sale (making one adjustment to sales strategy at least half a month). Lastly, the HQ can implement salesperson promotion for specified styles: setting a commission of $\mathrm{X}$ yuan for one piece sold at the original price. If dull sale persists after such salesperson promotion, the HQ can promptly employ other promotional strategies. Such supply chain model can help product managers simplify daily job and concentrate on the formulation of sales strategies.

\section{SEMIR Production and Distribution Collaboration Model of Supply Chain}

Besides the abovementioned classical quick response model of Sell-one-Replenish-one, other garment enterprises adopt their own unique supply chain management model. SEMIR is one example. SEMIR, founded in 1996, is a casual wear enterprise and famous for "virtual operation" in China. With the idea of Production and Distribution collaboration in supply chain management, SEMIR has created a fast and efficient supply chain. The core sections of this supply chain include product combination, band plan and ordering-in-advance, and order execution and supplemental order. The details are analyzed as below.

Product portfolio: SEMIR divide all products into 3 categories: basic styles (accounting for about 15\%), popular styles and fashion styles. The HQ only prepares production proposal for basic styles, including demand plan and style retaining plan, etc.. Furthermore, the HQ will, during internal evaluation section, make detailed planning of products, including detailed planning for various styles and structural direction of commodity combination. 
Band plan and ordering-in-advance: the band plan requires the company to estimate the market demand for various styles on the internal evaluation meeting. Some companies estimate the demands even before internal evaluation. Before making the ordering-in-advance decision, the manufacturing, merchandise and sales departments will discuss together whether to order in advance or not and the quantity of orders-in-advance. The merchandise department will makes final decision and place an orders-in-advance. During the process, the company shall pay attention to the ordering time and the proportion of orders-in-advance: orders-in-advance usually account for about $30 \%$ of that season's demand. The 30\% orders-in-advance are apportioned between before-the-internal-evaluation and before-the-buying-meeting. Orders-in-advance before the internal evaluation are only placed for the basic styles and some orders are only for material preparation.

Order execution and supplemental orders: SEMIR employs state-of-art ERP system and creates 4 types of order catering to requirement of different operations and facilitating analysis. The 4 types are: orders-in-advance, orders from the fashion show and buying meeting, supplemental orders before launch and additional orders after launch. Regarding issues of supplemental orders and additional orders, the HQ, by comparing the actual orders placed at the fashion show and buying meeting with estimated demand, formulates a supplemental order plan on its own and further makes dynamic rolling estimates according to sales during the season. Supplemental orders of SEMIR are almost based on available inventory. Users can access inventory information in the system, make sales estimation and determine whether to place supplement or additional orders.

With strict controls over these aspects, SEMIR sees the continuous improvement of efficiency in its supply chain, which lays a solid foundation for a good sales performance.

\section{JOEONE Production-Distribution Collaboration Model of Supply Chain}

Besides the remarkable success of SEMIR's Production-Distribution Collaboration model of supply chain, JOEONE, the representative of Fujian in man's garment, also has its own successful Production-Distribution collaboration model of supply chain. JOEONE dedicate itself to the development and manufacturing of high-end man's garments. Their products are famous for elegant design, rich variety, quality materials, delicate tailoring and outstanding quality. Just as SEMIR, the key elements of JOEONE's supply chain management also include: product portfolio, band plan, and planning/manufacturing mode and replenishment, but they are different in some details.

Product portfolio: JOEONE's products are also divided into 3 categories: basic styles, fashion styles and concept styles. The basic styles, accounting for about $15 \%$ of all styles, are only changed little or developed continuously year by year, which essences are accumulated and refined each year. Fashion styles, accounting for more than $70 \%$ of all styles, are developed by the HQ according to the theme of each season. Concept styles (innovation styles), accounting for about $15 \%$ of all styles and usually used for window display and promotion, are must-order styles.

Band plan: During merchandise planning, JOEONE's sales department will, according to historical sales performance and customer feedback, propose suggestions on the proportions of basic, fashion and concept styles, inventory unit (SKU), price ranges, etc., which help the management estimate sales and recommend themes, etc.. Next, the merchandise planning director, in consideration of the input from the sales department, formulates merchandise proposals and keeps material proposals synchronized to the merchandise proposals. Thirdly at the ordering stage, SKU band plan is made within 7 days after buying meeting and is then delivered to the greater supply chain deputy director and the sales deputy director for confirmation.

Planning/manufacturing mode and replenishment mode: JOEONE has adopted multiple manufacturing/planning modes, primarily including make-to-stock, make-to-order, custom-to-order (customized and group-purchased products). As to the styles and time of manufacturing-in-advance, the HQ will take some basic styles and all concept styles as the possible objectives of manufacturing-in-advance, examining the risk premium to determine whether to manufacture in advance and place an order after the second evaluation meeting (internal evaluation) at earliest, and take common materials as long-term preparation. In the aspect of replenishment, JOEONE implements 2 replenishment modes simultaneously, including estimate-based supplemental orders from available inventory and temporary supplemental orders.

Effective functioning of these stages in the supply chain ensures that JOEONE is able to balance all Production \& Distribution plans and to improve the overall efficiency of the supply chain.

\section{YOUNGOR "Wine Cup" Model of Supply Chain}

Beyond the successful cases of Production \& Distribution Collaborative supply chain, YOUNGOR, a well-established company in the man's garment industry, employs a "wine cup" mode of supply chain to ensure the effective functioning of supply chain. Through 30 years of development, YOUNGOR has established a vertical industrial chain of textile and garments led by its own brand garments. The company designs and develops products 
targeting at 3 consumer groups, including international business wear, administrative business wear and business casual wear. It has established brand characteristics of maturity and confidence, steadiness and containedness and aspiring for quality life. YOUNGOR's "wine cup" model of supply chain mainly covers three ideas: "push" supply chain, "pull" supply chain and quick response supply chain. The following is the details about YOUNGOR's supply chain.

"Push" supply chain: in this section, YOUNGOR implements the order-based push-type mass production mode. After accepting order, it will arrange material manufacturing, garment manufacturing and then distributes products to point-of-sale (POS) terminals. Moreover, YOUNGOR has the planning interval changed to be one time every 3 months, which ensures emerging driving force in the pushing stage to propel following stages.

"Pull" supply chain: in this section, YOUNGOR implements the pull-type just-in-time production mode without orders. It integrates the retail POS system, distribution system, finished garment ERP system and material ERP system. In order to ensure its effective functioning, it makes store become transparent "wine cup" and therefore the system can clear the inventory account of each store every day and transfers the data to the distribution center, enabling products to be delivered without orders.

Quick response supply chain: when establishing the quick response supply chain, YOUNGOR firstly set up the rolling supply chain plan and rolling estimate mechanism, making weekly rolling estimates on basis of monthly plan. Next, YOUNGOR, according to the rolling estimates, adjust the difference between actual demand and estimate order, reduce dull sale and sellout. Meanwhile, YOUNGOR also attempts mass customized production, and designing based on consumer's physical figure, social status, price endurance and dressing condition, in order to cater to the needs of different consumers. Lastly, YOUNGOR operates with 1 HQ and 3 systems, which simultaneously supports the 3 modes: make-to-order, make-to-estimate and custom-to-order.

With the management and establishment of the "wine cup" model of supply chain, YOUNGOR products can continuously meet market demand and cater to different consumers' needs. YOUNGOR gradually becomes a highly competitive enterprise with accurate product positioning and garment functions finely categorized.

\section{Conclusions}

It can be observed that different enterprises have made different supply chain stages. Some enterprises emphasize product structures, making use of product features to establish their differentiated supply chain. Some enterprises focus on ordering patterns split, combining future and current commodities and achieving differentiated response speeds. Some focus on terminal channels and inventory, optimizing channel logistics and inventory structures, optimizing the channels' replenishment mode. Viewed from actual results, those brand companies have been seen some progress in their supply chains, but only different from each other in performance of response speed, inventory pressure, etc..

Hence, other garment brand companies in China may, according to their product features, supply chain structures and capabilities, control capabilities over channel resources, inventory pressure and other factors, make use of other companies' optimized experience and formulate optimized supply chain program suitable for their development to improve company performance.

\section{References}

Fan, Chongjun (2004b). Informatization of Enterprises and Its Interaction with the Promotion of Enterprise Management. Shanghai Enterprise, 6, 34-37.

Fan, Chongjun, Xiong, Honglin, Zhang, Haiying, Liu, Wujun, Wang ,Liqiang, \& Song, Xiaohui. (2009). Analysis of network security and risks prevention strategies of Hongqiao Airport West Terminal. Computer and Information Science, 2(3), 46-52.

Fan, Chongjun. (2004a). Strategically Programming of Information Technology under Group Management Mode. Construction Machinery and Equipment, 35(9), 34-37.

Fan, Chongjun. (2006). Choice and Implementation of ERP in Automobile Industry. Manufacturing Automation, 12, 42-46, 67.

Liu, Xiaoming, \& Deng, Weimin (2010). Sell-one-Replenish-one: a New Garment Sales Pattern. Enterprise Management, (12), 76-78.

Zhou, Liangyi, \& Zhu, Qinwen. (2007). Supply Chain Strategy and Management of Garment Groups. Logistics Technology, (2), 218-220. 